\title{
Path Decision for Beautiful Countryside Construction Based on Agricultural Development Mode Transformation
}

\author{
Liu Xu ${ }^{1}$, Tang Huajun ${ }^{2}$, Yi Xiaoyan ${ }^{3}$, Zhao Junwei ${ }^{3}$, Yin Changbin ${ }^{3}$ \\ 1. Chinese Academy of Engineering, Beijing 100088, China \\ 2. Chinese Academy of Agricultural Sciences, Beijing 100081, China; \\ 3. Institute of Agricultural Resources and Regional Planning, Chinese Academy of Agricultural Sciences, Beijing 100081, China
}

\begin{abstract}
New opportunities for beautiful countryside construction have been created by a transformation of the agricultural development mode. This paper systematically reviews the problems and challenges associated with this process, and discusses a path decision for beautiful countryside construction that is based on the requirements of ecological civilization construction. It then examines the concept of beautiful countryside construction, which entails the strengthening of comprehensive planning and management in rural areas, food safety, coordination of the development between farming and animal husbandry, active promotion of the integration of rural industries, and the implementation of beautiful countryside construction projects. Finally, this paper puts forward policy suggestions to accelerate beautiful countryside construction.
\end{abstract}

Keywords: ecological civilization; agricultural development mode transformation; beautiful countryside construction; sustainable development

\section{Introduction}

The 18th National Congress of the Communist Party of China established the strategic task of ecological civilization construction, identified the "five-in-one" strategic development pattern, and proposed the construction of a beautiful China. The CPC Central Committee and State Council's Opinions on Accelerating the Construction of Ecological Civilization 2015 specifically highlights the objective of "to speed up the beautiful countryside construction." As an important part of the construction of a beautiful China, beautiful countryside construction has a direct impact on the level and process of this stated aim. Based on the connotation and essence of the beautiful countryside, it is the only way to promote the transformation of the agricultural development mode and promote the integration of primary, secondary, and tertiary industries. It is also an important starting point for the construction of rural ecological civilizations, which is an effective way to coordinate urban and rural development, promote urban and rural integration, and an important means to accelerate the process of new urbanization.

\section{Opportunities and challenges faced by beautiful countryside construction}

China is a great agricultural country in which agriculture is related to national food, resource and ecological securities. Since 2004, there has been significant advancement in China's agricultural industry including a historic "twelve consecutive

Received date: June 22, 2017; Revised date: July 18, 2017

Corresponding author: Yin Changbin, Institute of Agricultural Resources and Regional Planning, Chinese Academy of Agricultural Sciences, Professor. Major research field is utilization and management of agricultural resources. E-mail: yinchangbin@caas.cn

Funding program: CAE Advisory Project “Several Strategic Issues on Eco-Civilization Construction (Phase II)” (2015-ZD-16)

Chinese version: Strategic Study of CAE 2017, 19 (4): 033-039

Cited item: Yin Changbin et al. Path Decision for Beautiful Countryside Construction Based on Agricultural Development Mode Transformation. Strategic Study of CAE, https://doi.org/10.15302/J-SSCAE-2017.04.006 
increases" in grain production, and the achievement of "twelve rapidly consecutive increases" in farmers' earnings. However, the deep-seated contradictions that have accumulated in longterm extensive operations gradually present themselves; the sustainable development of agriculture is facing multiple challenges; water and soil resources are poor and are allocated unreasonably; the excessive use of fertilizer and pesticides and the improper handling of livestock and poultry manure aggravate environmental pollution and seriously damage the agricultural ecosystem; The bad conditions of the countryside have not been fundamentally changed, but the traditional way of agricultural production is difficult to sustain.

\subsection{Opportunities open to beautiful countryside construction}

2.1.1 The construction of a beautiful countryside is an important part of constructing a beautiful China

The 18th National Congress of the Communist Party of China requires that the beautiful China construction is made a priority in the construction of an ecological civilization. According to the statistics, the urbanization rate of Chinese residents' population is $57.4 \%$ [1]. In 2016, nearly half of them still lived in rural areas. Moreover, the ecological shelters of forests, grasslands, rivers, and wetlands are all located in rural areas [2]. Therefore, the implementation of a beautiful countryside construction is a prerequisite of the construction of a beautiful China. The aim of "scientific planning for an efficacious layout, cleaning of villages for a beautiful environment, the initiation of business activities for improving the quality of life, and the advocacy of civilized customs to achieve a high quality of living" requires further enrichment of its connotation and an expansion of the field. This includes the comprehensive improvement of rural living and production conditions to build a beautiful countryside with high standard of living and the creation of an ideal climate for business and tourism.

2.1.2 The construction of a beautiful countryside is an important starting point in the promotion of rural ecological civilization construction

In 2015, in accordance with the programmatic document of China's ecological civilization construction, CPC Central Committee and State Council's Opinions on Accelerating the Construction of Ecological Civilization, was officially released. The construction of a rural ecological civilization is an important aspect of ecological civilization construction, which is related to the progress and effect of the overall construction of ecological civilization in China. If there is no rural ecological civilization, then there is no national ecological civilization. However, many regions have different degrees of "focus on city but ignore countryside" and the phenomenon of "dirty, disorder, bad" has existed in rural areas over the years in the construction of an ecological civilization.
2.1.3 The construction of a beautiful countryside is the only way to promote the transformation of rural economic development

In 2016, "Document No. 1 of the Central government" highlighted that we should "accelerate the transformation of agricultural development; maintain the stable development of agriculture and the consecutive increase of farmers' income, take the environment-friendly agricultural modernization way of efficiency production, product safety, resource conservation." Beautiful countryside construction is not only conducive to the promotion of the adjustment of rural economic structure, to achieve the structural reform of the supply side, to promote the transformation of a people's production and consumption patterns to improve the rural living environment. However, it should also be conducive to the intensive and efficient use of resources to effectively coordinate the population distribution and the support capacity of resources and the environment, in addition to the promotion of a sustainable development of an economic society [3].

2.1.4 The construction of a beautiful countryside is an important breakthrough in accelerating the process of new urbanization

The "new urbanization strategy" proposed at the 18th National Congress of the Communist Party of China requires that the concept of a beautiful countryside construction be synchronized with the new urbanization, thrust. Specifically, the beautiful countryside must be exemplified by construction driven by urbanization in which achievements are based on the beautiful countryside construction. The latter is the practical foundation to achieve urbanization and in this process, address food problems, land, human capital and in addition to addressing issues related to endogenous growth based on the stable construction and improvement of beautiful a countryside. Urbanization is the driving force of the beautiful countryside construction in which problems related to investment, residence registration, public service and social security must be solved via the measurable advancement and expansion of this concept. During the acceleration of the process of new urbanization, beautiful countryside construction becomes an effective enabler to address new situations, problems and challenges.

\subsection{Problems faced by beautiful countryside construction}

\subsubsection{Increasingly difficult constraints on the agricultural} resource environment

According to the results of the second national land survey, China's per capita cultivated land is only $0.1 \mathrm{hm}^{2}$ and the per capita water resource is only a quarter of the world's per capita water volume. The effective utilization coefficient of farmland irrigation water is 0.2 lower than that of the average level for developed countries and the effective utilization rate of agricultural water is only about $50 \%$. Moreover, phenomena such as flood irrigation and over-irrigation are more common. In China, one 
cubic meter of irrigation water produces $1 \mathrm{~kg}$ of grain and $0.5 \mathrm{~kg}$ of grain is produced per millimeter per mu precipitation, which is only one half that of other developed countries [4]. China's usage of fertilizer per hectare of land is over 4 times that of the world's average [5], but the amount of fertilizer which actually results in crop growth is just over $30 \%$. China's annual use of pesticides is about $1.8 \times 10^{6} \mathrm{t}$ and the agricultural plastic film left on farmlands each year is in excess of $1 \times 10^{6} \mathrm{t}$ [6]. The effective disposing rate of livestock and poultry manure is less than $50 \%$ and straw burning is very common. China's soil erosion area is approximately $2.95 \times 10^{6} \mathrm{~km}^{2}$, the annual amount of soil erosion is $4.5 \times 10^{9} \mathrm{t}$, the sandy land area is approximately $1.73 \times 10^{6} \mathrm{~km}^{2}$, the stony desertification area is $1.2 \times 10^{5} \mathrm{~km}^{2}$, and grassland overloading and overgrazing problems are still persistent [7].

2.2.2 Three serious problems exist in rural areas while rural development lacks endogenous motivation

With the accelerated industrialization and urbanization, a large number of high-quality rural production factors flow into the city. The rural industry realizes the leap-forward development is faced with many problems such as the gradual weakening of traditional agriculture, the gradual marginalization and hollow-out of the countryside, a reduction in the number of farmers engaged in agricultural production and the gradual decline of rural areas. The three most important problems can be categorized as the hollow-out of the countryside, agricultural deindustrialization and the aging of rural labor. Of the three, the hollowing out of the village is in a period of rapid increase and lots of rural labor flow outside. Thus huge rural fund outflows and the rural economic development is quite slow and even stagnant. Moreover, without the engine of economic growth, the income of villagers is low given the single earning source. With a huge rural labor outflow, the aging of the rural labor force is further exacerbated. Existing literature indicates that the proportion of the labor force over 50 years old in China will reach $50 \%$ by $2020[8,9]$.

2.2.3 Enhancing agricultural efficiency and increasing the income of farmers is difficult and the structural reform of the supply side exerts strong pressure

China's agricultural production costs has increased rapidly. In particular, the annual growth rate of productive service cost has increased from $8 \%$ to $9 \%$ and the "floor" of agricultural production cost is rising [10]. In light of the pressure of the disordered relation between international and domestic agricultural prices, domestic and foreign prices have a gap of about 400 to 800 yuan per ton if the price of grain is fixed by the wholesale price. As such, the domestic price of grain per ton is $400-800$ Yuan higher than that of the international market [11]. Due to the dual marketing forces of the uplifting "floor" and the top "ceiling" of agricultural products cost, in an analogy to a room, the available space is gradually reduced and this leads directly to difficulties in enhancing agricultural efficiency and increasing the income of farmers.
2.2.4 Connection of rural primary, secondary, and tertiary industries is not close enough and the value added to the product is low

The link among China's rural primary, secondary with tertiary industries is not sufficiently close and the overall development level of agricultural industries is not high. For example, the "production and sales" of agricultural products has not formed a highly efficient and complete industrial chain. The processing industry for agricultural products started late and was hindered by a poor infrastructure, outdated equipment and a low processing conversion rate. The transportation patterns of agricultural products are archaic and the transportation cost is high with great losses. Moreover, the scale of agricultural production is small, the degree of organization is low and the agricultural versatility is far from the required level. In addition, the maximization of the value of industrial chain is not achieved [12].

2.2.5 Weak rural infrastructures and single public service supply model

Infrastructures and public service facilities are seriously lacking. The utilization rate of existing cultural facilities is low and land resources are wasted. In particular, village construction lacks proper planning and the choice of the building site is arbitrary. China's supply model of existing rural public services mainly includes the monopolistic supply model with the government as the mainstay, the contract supply model with the market as the mainstay, and the voluntary supply model with the society as the mainstay. However, it is difficult to ensure the quantity and quality of each model and they each suffer from a "free ride" phenomenon and a weak force of social organization in addition to other problems [13].

\section{Path decision of beautiful countryside construction}

The 18th national congress of the communist party of China takes ecological civilization construction into the overall general "five-in-one" arrangement to provide solid institutional guarantees for agricultural sustainable development. Three ideas, namely green development, circle development, and low-carbon development are deeply rooted in people's hearts, and policy efforts to strengthen agriculture benefit and enrich farmers and lay a solid foundation for the construction of the beautiful countryside. This construction should be aimed at promoting the development of agricultural industries, increasing the earnings of farmers and enriching them. It should also entail improving the local living environment and should regard the comprehensive improvement of the rural environment as the starting point to expand and improve the idea of a new rural construction. This is necessary to develop agricultural production and the emergence of rural industries. The inheritance of the ecological culture, the nurturing of a new spirit and the building of a production and 
way of living in accord with protecting the resource environment is necessary. To build a beautiful countryside with "efficient production, beautiful life, habitable environment, and a harmonious atmosphere," it is also necessary to thoroughly promote the development of modern agriculture, the construction of ecological civilization, the management of rural society and green development.

\subsection{Building an operating system deeply composed of primary, secondary, and tertiary industries}

The transformation of the agricultural development mode can actually achieve an efficient supply of agricultural products with a reasonable structure and strong guarantee, and can reduce production cost and increase agricultural benefit and competitive power. In addition, it can also can help to build up the "large agriculture, abundant food" idea and extend the industry chain by horizontal and vertical integration. First, a main body composed of diversified industries is cultivated to encourage and support family farms, leading enterprises, professional cooperatives, and social service organizations to perform various forms of industrial integration development. Second, interest of the coordination mechanism is established based on the integration of rural primary, secondary and tertiary industries and the reformation of land and the collective of assets shareholding system is encouraged for qualified areas to in addition to building a strategy alliance of technology innovation. The appreciation of agricultural industries through sharing split to households and taking a joint-stock cooperative system is important. Third, the exploration of a new mode "Internet + modern agriculture" and the use of Internet information technology in the modern agricultural industry is investigated to encourage network transformation of the field cultivation, livestock and poultry breeding, fishery production and others. Fourth, the deep promotion the process of "one village one product" and "one village one industry" and the acceleration of the development of the agricultural products storage, transportation, preservation, Packaging, etc. is encouraged. This will facilitate the transformation of the agricultural products processing industry from the original scale expansion, the simple consumption of resources, decentralized development for quality improvement, structural optimization, technical upgrading, intensive resources, and the development of industrial agglomeration.

\subsection{Promoting the combination of planting and breeding, agriculture, and animal husbandry}

This entails the active exploration of a new ecological agriculture with high efficiency integration of grain, agriculture, animal husbandry, fishery, agricultural agronomy, and others. The ultimate goal is the optimization of the structure of planting and breeding by vigorously promoting an ecological cycle technol- ogy and the production model with the combination of planting and breeding. First, construct a farming system which combines farming with animal husbandry, in the northeast cold area and implement an eco-friendly farming systems, such as for corn and soybean rotation, corn and alfalfa rotation, and wheat and soybean rotation. In the northern area with both farming and animal husbandry, the main focus is on the development of watersaving, drought-sensitive, high resistance and other crops and pasture. In the northwest arid zone, a decision on what to plant is made according to the amount of available water, the change of the grain which needs less water, and whether a drought-resistant grass is utilized. In the south region with multiple crops, many combination forms of the intercropping mode or the relay intercropping mode is used to cultivate gramineae and legumes, tall stalks and short stalks crops, paddy and upland field and other forms. Second, according to the demonstration plot of efficient ecological agriculture construction, expansion of the integration of agriculture and animal husbandry and the range of ecological animal husbandry pilot allows the support of main grainproducing areas to develop animal husbandry. In addition, the promotion of "digested straw return to field" (return the straw whose protein, cellulose and other nutrient substances has been digested by a herbivore to the field) technology, and the active development of grass and animal husbandry to support cultivate alfalfa and Silage corn and other forage is noteworthy. Circular agriculture pilots of grain feeding and a combined planting with breeding mode should be established.

\subsection{Strengthening rural comprehensive planning and environmental governance}

Planning should be paramount and represent the starting point of scientific design and should facilitate future development. Improvement of the level of village planning and the setting of an overall village plan to unify village construction and the governance of the living environment based on the realities of various regions should be considered. There should be a focus on strengthening the planning and management of the homestead and rural collective construction land so that they can be preserved. In addition, the enhancements to complement and improve the public infrastructure to obtain a reasonable layout and complete functions should be undertaken. Improvement of the traffic planning and the layout of buildings to improve the appearance of the village in terms of beauty and comfort, in addition to convenient and fast transportation should be pursued. The classification, collection, and treatment of rural household garbage should be carried out, drinking water purification systems should be improved, the water resources should be better monitored, and the governance of the surrounding environment in rural areas should be improved. Environmental safety standards for the use of agricultural chemicals, such as chemical fertilizers and pesticides, should be discussed and formulated. 
The forbidden livestock and poultry breeding areas should be delimited, breeding areas should be appropriately defined, and the environmental governance of the animal husbandry industry should be strengthened. Efforts to inspect and control the pollution of industrial and mining enterprises on rural areas should be reinforced. The quality of water in rural areas should be improved, the condition of rural toilets should be bettered, village homes should be renovated, ditches should be cleaned, and villages should be made green and beautiful [14].

\subsection{Protecting and excavating the traditional culture of agriculture}

Agricultural culture is the result of long-term accumulation of ways of practice and the wisdom of the field workers. Its multifunctional value is embodied in the following four aspects: productional, ecological, social, and cultural functions. Agricultural culture plays an important role in maintaining the sustainable development of rural areas [15].

Specific projects that are based on scientific planning should be implemented in harmony with local conditions. Further, the protection around houses or villages with regional agricultural traditions should be strengthened. In rural areas, the traditional rural styles and inheritances of agricultural culture should be upheld; the agricultural cultural heritage should be excavated and protected and considered of importance, and landscape tourism of villages with traditional agricultural culture should be developed. Regional rural cultures should be promoted for the benefit of the villagers, mechanisms that safeguard and ensure investment in such rural cultures should be established, knowledge education of ecological civilizations should be strengthened among the villagers, the famers' awareness of ecological civilization should be improved, and a new rural ecological civilization should be constructed.

\section{Implementing beautiful village construction projects}

\subsection{The propulsion of the precise fertilization project}

To reduce agricultural non-point source pollution, increase agricultural efficiency and quality, and use increasing farmers' incomes as a foothold, emphasis has been laid on the spread of formulated fertilizers and the changes in methods of fertilization. An overall arrangement to conduct basic analysis, such as the chemical examination of soil and of local conditions, was made. Based on major crops, such as grain and cotton oil, expand the region chosen for soil testing and application of formulated fertilizer to economic horticultural crops was determined. Various forms of information guidance services and precise fertilization models in soil testing and formulated fertilizer application was carried out. Further, the training of the new management mode was strengthened and the famers' consciousness of precise fertilization was comprehensively reinforced. Cooperation among schools in every area, to intensify technical support to the project, was strengthened, and all key technologies were put in place in order to improve the levels of precise fertilization. Adhering to the government's laws, and considering farmers as the main body, enterprises as the major drive, social participation, and innovative implementation as the mode, scientific research, teaching, enterprise, and farming to construct a long-term mechanism were jointly promoted. The construction and analysis of the database was further done, and attention was paid to the collection and arrangement of the data.

\subsection{Demonstration projects regarding comprehensive utilization of agricultural waste}

Demonstration projects regarding the comprehensive utilization of agricultural wastes include: first, the comprehensive utilization of straw. At present, the comprehensive utilization of straw is mainly in feed, fuel, and fertilizer, and as raw materials and basic material. Such application fields comprehensively utilize straw through the making of straw silage, gasification and solidification to supply heat and electricity, or returning the straw to fields by machine, or compressing models, etc. They also promote the development of industrialization and broaden channels of the straw's utilization; implement the methods to return straw to fields by machine and the height of stubble to advance the rupturing of the straw to the field. Second, recycling of remnant films and packages of pesticide products. The comprehensive utilization mode of remnant films is explored, the construction of recycling outlets of agricultural residues is supported and the relevant enterprises to strengthen recycling effort is encouraged. Further, the technology research and promotion of biodegradable agricultural films is sped up, the problem of "white pollution" caused by a great deal of agricultural residues is effectively relieved. Moreover, the rules and regulations for the harmless treatment of packages of pesticide products are improved that rely on pesticide dealers to set up waste recycling stations for packages of pesticide products and uniformly collect and recycle the package wastes with compensation. Third, comprehensive use of livestock and poultry manure. According to the idea, "separation of dry and wet, diversion of rain and sewage, combination of planting and breeding," a batch of facilities used to collectively recycle and transport livestock and poultry waste is constructed, fertilizer is made from solid animal waste, and sewage is treated and efficiently disposed.

\subsection{A demonstration project on rural renovation and land use planning}

Strengthening the use of " $3 \mathrm{~S}$ " technology, that is remote sensing (RS), geography information systems (GIS) and global 
positioning systems (GPS), in the land use planning of villages was the goal here. GPS can accurately locate the position of the land to use, RS can realize round-the-clock, real-time remote monitoring, and accurately monitor the change of rural land, and GIS can conveniently collect, store, update, analyze, and export data, and conduct the operation of data and attribution of information through human-computer interaction and the viewable mode. The " $3 \mathrm{~S}$ " technology is used in rural land use planning, and in real-time tracking and monitoring of the change of rural land, so that the land control system in rural areas can be effectively implemented.

\subsection{Promotion and demonstration of rural infrastructure projects}

Planning ahead and achieving coordinated development, uniformly planning basic rural facilities, such as water, electricity, roads, gas, and public utilities of villages are some of the goals of this project. Reinforcing the construction of rural infrastructures, the realization of hardening road surface all the way up to the doors of households, the diversion of rain and sewage, the above-mentioned three ways of waste utilization, promotion of the collectively comprehensive control of rural garbage, sewage treatment, bare houses, old houses, village greening, and soil environment are further goals of this project. Creating a batch of demonstration counties (city, district) with livable environment, and implementing a new round of beautiful countryside construction projects; improve the mechanism of rural biogas construction and management; continuously carrying out the renewal and upgradation of the rural power system and the project on taking broadband into villages, are included in the promotion and demonstration of rural infrastructure projects. Taking the new mode of rural residential land use and combining it with rural industrial innovation and rural environmental governance was also part of this endeavor. The research and development of rural infrastructures should pay attention to low input and adaptability to ensure that the villagers can use this infrastructure and can operate and implement them easily.

\subsection{Training projects of new professional farmers}

Strenuous efforts should be made to increase the numbers of new professional farmers, to solve the "weakness" of rural labor force and speed up the establishment of a new professional farmers training system based on the "three-in-one," the education training, standard management, and policy support. Improvement of the nonprofit farmer training system and acceleration of the course of new professional farmer training and continuous education. The combination of production should be strengthened, study and research of farmer training and push the integration of education, competence, and pioneering training through kinds of modes, like the school-enterprise cooperation, collec- tive education and the integration of production and education. College graduates who are interested in pioneering work and the new generation of migrant workers should be encouraged to return to their hometowns and start up their own business or get jobs.

\section{Policy recommendations}

\subsection{Scientific planning and the construction of villages' infrastructures on the basis of local conditions}

This involves the establishment of effective and perfect village plan-making systems from the macroscopic to the microcosmic level such that the planning process is more robust and involves a scientific design to ensure that there is effective allocation of space, particularly for future development. There should be village construction guidelines to facilitate the classification of villages, familiarity of local conditions, the guidance of classification and the control of grading. To improve the level of village planning, an overall plan should be implemented for the village based on the integration of village construction and the governance of the living environment. This should be done with a focus on strengthening the planning and management of the homestead and rural collective construction land use to save the village construction land, in accordance with local conditions Moreover, the support and improvement of public infrastructure should be strengthened, and the layout should be made reasonable and functional. The traffic organization and building layout should also be improved and villages should be kept clean and orderly, the house should be beautiful and comfortable, and the traffic should be well-controlled and free-flowing. Village planning should be consistent with the needs of the villagers and the local conditions, while highlighting regional features. The construction of villages should focus on optimizing the ecological environment, improving the living environment, and the further development of the traditional culture. The layout of village spaces should be optimized according to functional localization and the needs of the residents with moderate development of the infrastructure and public service facilities.

\subsection{Promotion of the construction of a beautiful countryside} and the building of new industries

This entails the comprehensive development of the top design and the strengthening of the characteristic creativity. In addition, the creation of batches of beautiful fields with serve multifunction with a pleasant environment and an attractive scenery. Another key feature is the promotion of the combination of agriculture and animal husbandry and the deep integration of primary, secondary, and tertiary industries. In is also important to create a group of industrial belts and groups to exploit a competitive, environment-friendly recreational agriculture with 
a rich culture. Other noteworthy aspects include the promotion of the development of agricultural production, the improvement of the living environment and the cultivation of a civilized spirit, the development of rural industries, the improvement of the rural living environment and the inheritance of the agricultural culture. It is also necessary to foster civilized behavior, establish production and coordinated living by protecting of the resource environment, and to thoroughly promote the development of modern agriculture. Finally, the construction of an ecological civilization and the management of rural society to construct a beautiful village with "efficient production, beautiful life, livable environment, harmonious atmosphere" are important.

\subsection{Optimization of agricultural function zone and formulation of developmental plans for the combination of green planting and breeding}

The implementation of the main functional area planning should be sped up and a national agricultural space planning system should be established to clearly delimit the management of production, living and ecological space development. The uses of control and the formation of a reasonable land-use structure for farming, forestry, and animal husbandry should be considered. Moreover, the focus should be directed to both the saving and the highly efficient utilization of agricultural resources, the utilization of agricultural waste, and clean production in the expansion process of the agricultural industry chain. This is necessary to put forward ideas, procedures, targets, modes, and related engineering measures in addition to important support fields and guarantee system. Some special planning on water, land, fertilizer, labor and cost saving should be devised in addition to a comprehensive utilization of agricultural resources and the adjustment of agricultural planting systems in typical regions. These special planning helps to put forward development goals, priorities, and policy measures for long-term planning in agricultural development. In addition, the promotion of the comprehensive utilization of ecological circling planting, breeding and waste, and the focus on supporting the construction of supporting infrastructure for the integrated development of agriculture and animal husbandry are critical aspects.

\subsection{Building a long-term mechanism of rural infrastructure construction}

One of the objectives is the establishment of the infrastructure of a beautiful village with "government leading, farmers as mainstay, social assistance and market operation," and to achieve a diversified supply model for rural public services. The government organization should strengthen its leadership, clarify the main responsibilities of governments at all levels, and play an active role in guiding, supporting, and supervising. They should also extensively gather public opinions, respect the farmers' main position, and mobilize the enthusiasm of farmers to participate in the construction of beautiful villages. It is also expected that they would build a market-based platform to explore the combination model of government and social capital, and guide all kinds of social capital to be invested in the beautiful countryside construction. At the same time, they should establish the operation and maintenance mechanism of rural public services through governmental purchase of services, adopt a public-private partnership (PPP) model, and build a long-term mechanism of rural infrastructure construction. It is expected that a fiscal tax policy will be set up and improved to encourage production and the utilization of agricultural resource-saving and environment-friendly products. This is in addition to the support of the development of green industries, agricultural resource-saving and environment-friendly enterprises.

\subsection{Reinforcement of the integration and demonstration of green agriculture and rural development technology}

This aspect involves reinforcement of the integration of agricultural industry chains, the development of clean agricultural production technology, the exploitation of green production technology and multi-level transformation of agricultural resources, in addition to the promotion of economic and efficient utilization of resources and waste recycling technology. It is also necessary to establish standards for circular agriculture technology, the improvement of the construction technology of rural ecological towns, the strengthening of efforts related to construction and investment in green technology for rural life consumption. Additional important aspects include the performance of integration and integrated research, the set up and improvement of the technical innovation system, technical demonstration and the promotion system of agricultural development. Finally, in accordance with local conditions, the construction of a batch of demonstration areas for the integration of primary, secondary, and tertiary industries, ecological recycling agriculture and green village, are also key features.

\section{References}

[1] National Bureau of Statistics of the PRC. The level of urbanization has been continuously improved, the overall strength of the city has been markedly increased-The economic and social development since the Eighteenth National Congress of the CPC (series nine) [EB/OL]. (2017-07-11) [2017-07-13]. http://www. stats.gov. cn/tjsj/sjjd/201707/t20170711_1511794.html. Chinese.

[2] Wu Y F. Promoting the development of urban and rural areas by means of beautiful rural construction-Based on the study and thinking of the practice of beautiful rural construction in Tonglu $[\mathrm{J}]$. Economic Research Guide, 2014 (18): 26-30. Chinese.

[3] Yin C B, Cheng L L, Yang X M, et al. Path decision of agriculture sustainable development based on eco-civilization [J]. Chinese Journal of Agricultural Resources and Regional Planning, 2015, 
36(1): 15-21. Chinese.

[4] Zhang T L. Strengthen the construction of agricultural ecological civilization, promote the agricultural product quality security and agricultural sustainable development [J]. Soils, 2015, 47(2): 193-196. Chinese.

[5] Ye X Q. Evolution of trajectory, predicament and policy choice to transform Chinese agricultural development mode [J]. Reform, 2016 (6): 22-39. Chinese.

[6] Song H Y, Jin S Q, Zhang C Q. Promoting ecological civilization construction in rural areas through protecting agricultural environment and resource [J]. Journal of Hunan Agricultural University (Social Sciences), 2016, 17(5): 33-41. Chinese.

[7] Ministry of Agriculture, National Development and Reform Commission, Ministry of Science and Technology of the PRC, etc. National agricultural sustainable development plan (2015-2030) [EB/OL]. (2015-05-27) [2017-05-30]. http://www.moa.gov.cn/ govpublic/FZJHS/201505/t20150527 4620031.htm. Chinese.

[8] Yao W J. Seven years after the growth of security worries [N]. Guangming Daily, 2011-04-26(11). Chinese.

[9] Yin C B, Zhao J W, You F, et al. Research on the development strategy of agricultural modernization based on eco-civilization $[\mathrm{J}]$.
Strategic Study of CAE, 2015, 17(8): 97-102. Chinese.

[10] Zhang L C, Shen X F, Zhang H. Major tasks and main measures of agriculture and rural development in the period of the 13th FiveYear Plan [J]. Review of Economic Research, 2015 (62): 51-58. Chinese.

[11] Song Y P, Song F F. Torture the price of agricultural products 'ceiling' phenomenon [J]. Jianghan Tribune, 2015 (11): 5-10. Chinese.

[12] Dai X T. Analysis on the current situation, problems and countermeasures of Chinese agricultural industry value chain [J]. Agricultural Economy, 2016 (1): 6-8. Chinese.

[13] Fan H S, Tang H M. The mode selection and institutional design of rural public service under the new normal [J]. Journal of Jishou University (Social Science Edition), 2016, 37(1): 1-9. Chinese.

[14] Yin C B, Zhou Y, Liu L H. Theory and practice of recycle agriculture in China [J]. Chinese Journal of Eco-Agriculture, 2013, 21(1): 47-53. Chinese.

[15] Zhang C Q, Shen G Y. Multifunction of agricultural heritage and its industrial development and industrial convergence approaches [J]. Journal of China Agricultural University (Social Science Edition), 2016, 33(2): 127-135. Chinese.aa 